\title{
Lactate Disposal via Gluconeogenesis Is Increased During Exercise in Patients with Mitochondrial Myopathy Due to Complex I Deficiency
}

\author{
MARK J. ROEF, SATISH C. KALHAN, DIRK-JAN REIJNGOUD, KEES DE MEER, AND \\ RUUD BERGER \\ Department of Pediatric Gastroenterology [M.J.R.], Laboratory for Metabolic Diseases [R.B.], University \\ Children's Hospital, Utrecht, The Netherlands; Robert Schwartz, M.D., Center for Metabolism and \\ Nutrition, MetroHealth Medical Centre, Case Western Reserve University School of Medicine, Cleveland, \\ Ohio 44109, U.S.A. [S.C.K.]; Laboratory for Metabolic Diseases, Department of Pediatrics, University \\ Hospital, Groningen, The Netherlands [D.-J.R.]; Department of Clinical Chemistry, Vrije Universiteit \\ Medical Center, Amsterdam, The Netherlands [K.d.M.]
}

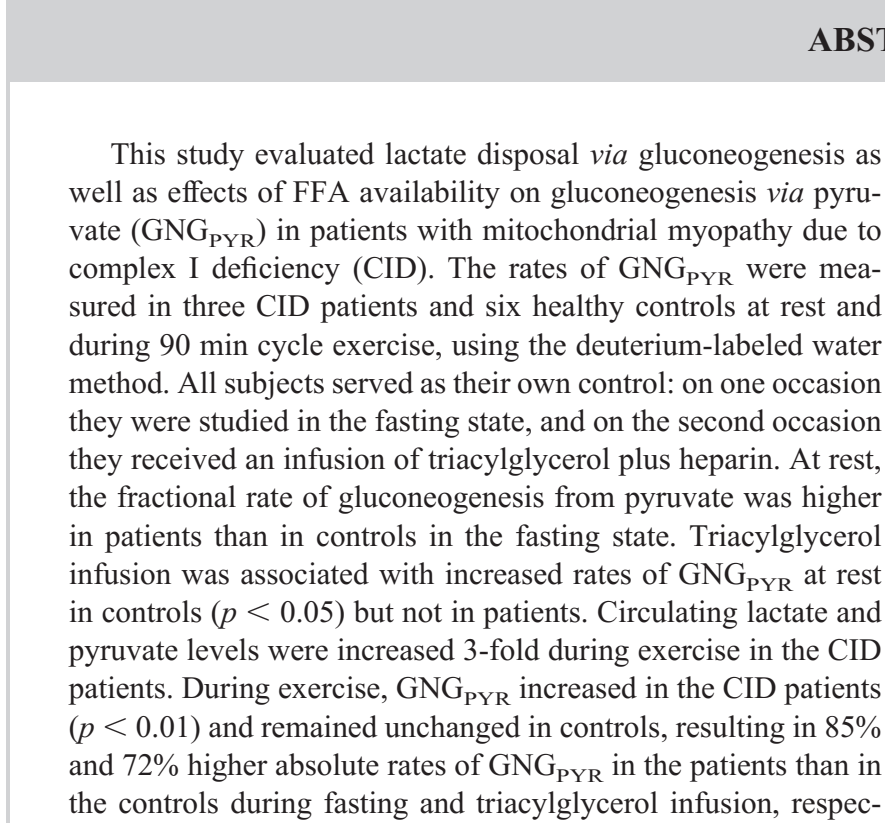

tively. During exercise, rates of $\mathrm{GNG}_{\mathrm{PYR}}$ were not different between fasting and triacylglycerol infusion within both groups. Our data show that 1) $\mathrm{GNG}_{\mathrm{PYR}}$ is increased during exercise in CID patients; 2) increased pyruvate availability contributes to the higher rates of $\mathrm{GNG}_{\mathrm{PYR}}$ in the CID patients; and 3) exogenous infusion of fatty acids is not associated with increased rates of $\mathrm{GNG}_{\mathrm{PYR}}$ in CID patients at rest or during exercise. $\mathrm{GNG}_{\mathrm{PYR}}$ is a significant mechanism of lactate disposal in exercising CID patients, but triglyceride infusion does not enhance their lactate disposal through this mechanism. (Pediatr Res 51: 592-597, 2002)
CID, complex I deficiency
GNG, gluconeogenesis
$\mathbf{G N G}_{\mathbf{P Y R}}$, gluconeogenesis from pyruvate
Ra, rate of appearance
TTR, tracer-to-tracee molar ratio

\section{Abbreviations}

Respiratory chain defects can give rise to many symptoms in any organ or tissue dependent upon mitochondrial ATP supply. CID is one of the more frequently encountered respiratory chain defects, and comprises the diminished ability of the mitochondria to oxidize NADH. Lactate levels and lactate-topyruvate molar ratios in plasma are elevated in CID patients, reflecting the elevated cytosolic $\mathrm{NADH} / \mathrm{NAD}^{+}$ratio in the patient's tissues. Isolated CID is of particular interest because of its potential treatment with high-fat diets. The rationale for this treatment is that fatty acid oxidation may potentially bypass the defect, as it provides, relative to carbohydrate

Received January 20, 2001; accepted December 5, 2001.

Correspondence and reprint requests: Kees de Meer, Department of Clinical Chemistry, Reception K, Vrije Universiteit Medical Center, P.O. Box 7057, 1007 MB Amsterdam, The Netherlands; e-mail: k.demeer@vumc.nl oxidation, the respiratory chain with more reducing equivalents as flavin adenine dinucleotide, whose electrons enter the respiratory chain distal of complex I. Fatty acid oxidation, as with a high-fat diet, was hypothesized to improve mitochondrial oxidation and to diminish lactate levels in CID patients. In empirical studies in myopathic patients with CID, triacylglycerol infusion compared with glucose had such beneficial effects during exercise, but, despite the presence of hyperlactatemia during resting, the triacylglycerol infusion did not decrease lactate levels or improve mitochondrial respiration in the patients' resting state $(1,2)$.

In continuation of these studies, in the present work, another pathway of lactate and pyruvate metabolism in CID patients was investigated, namely its conversion into glucose by the GNG pathway. The deuterated water method was used for the 
quantification of $\mathrm{GNG}_{\mathrm{PYR}}(3-5)$. Studies were performed both at rest and during exercise. To examine the effects of FFA availability $(6,7)$, GNG was quantified during the fasting state and in response to an infusion of triacylglycerol plus heparin.

\section{METHODS}

\section{Subjects}

Six healthy control subjects (two male and four female), age range 18-32 y, and three CID patients (all females, age range $16-29$ y) were studied. Their physical characteristics are listed in Table 1. None of the control subjects had a family history of diabetes mellitus or were taking any medications. Clinical and laboratory details of the three CID patients have been described in a previous article (2). Briefly, they were born from unrelated parents and suffered from easily fatigable mild muscle weakness dating back to early childhood. They showed no signs of CNS involvement. Their symptoms remained stable over time; exercise intolerance therefore dominated the clinical picture at the time of study. Fasting ( $0900 \mathrm{~h})$ plasma lactate concentrations ranged from 2.1 to $4.6 \mathrm{mmol} / \mathrm{L}$. CID was diagnosed with microscopic and biochemical investigations in freshly biopsied quadriceps (vastus lateralis) muscle, showing severely impaired oxidation of NADH-linked substrates, and an enhanced or normal oxidation of flavin adenine dinucleotide (reduced form) and cytochrome $c$-linked substrates, with a markedly decreased activity of complex I (NADH-ubiquinone oxidoreductase, EC 1.6.99.3) in all patients. The activities of the complexes III and IV were unimpaired or even increased. Mitochondrial DNA abnormalities (point mutations, i.e. 3243 $\mathrm{A} \rightarrow \mathrm{G}$ MELAS/PEO, $8344 \mathrm{~A} \rightarrow \mathrm{G}$ MERRF, $8993 \mathrm{~T} \rightarrow \mathrm{G}$ NARP, $11778 \mathrm{~A} \rightarrow \mathrm{G}$ LHON, deletions, duplications, or mitochondrial DNA depletion) have not been demonstrated in any of these patients, nor could a maternal pattern of inheritance be shown. A nuclear DNA mutation is therefore suspected, but this has not yet been proven.

The experimental protocol was approved by the Medical Ethics Committee of the University Children's Hospital
(Utrecht, The Netherlands). Written informed consent was obtained for each subject.

Pre-experiment testing. All participants reported to the laboratory at least $3 \mathrm{~d}$ before the experiments to perform an incremental maximal exercise test on an electrically braked cycle ergometer (Lode Instruments, Groningen, The Netherlands). Maximal workload and maximal oxygen uptake were assessed as previously described (8). Maximal workload in patients ranged from 55 to $60 \mathrm{~W}$, whereas in the controls it averaged $258 \mathrm{~W}$ (Table 1). The results of this test were used to calculate a workload equal to $15 \%$ of each subject's maximal workload, which was used in the exercise studies. Thus, patients exercised at a workload of only $9 \mathrm{~W}$ on the same cycle ergometer that was used for the incremental maximal exercise test. This cycle ergometer was designed to give reliable output at very low workloads. Workload in control subjects ranged from 36 to $65 \mathrm{~W}$.

\section{Experimental Protocol}

Subjects reported at the laboratory at $0730 \mathrm{~h}$ on two occasions, separated by at least $6 \mathrm{wk}$. A triacylglycerol or fasting study was performed, and assigned in random order. All subjects participated in both studies. Four days before each study, subjects were placed on a diet containing at least $200 \mathrm{~g}$ of carbohydrate daily. The subjects ate their last meals at $1800 \mathrm{~h}$ the evening before the day of the study. For measurement of GNG, they were given oral $\left[{ }^{2} \mathrm{H}_{2}\right] \mathrm{O}\left(>99 \%{ }^{2} \mathrm{H}\right.$; Isotec, Miamisburg, OH, U.S.A.), $5 \mathrm{~g} / \mathrm{kg}$ body water divided into four doses (at 2100, 2200, 2300, and 2400 h). Body water was estimated to be $73 \%$ of fat-free mass, which was assessed by skinfold measurement. Each study started at $0800 \mathrm{~h}$. One indwelling catheter was inserted into a cubital vein for infusion. Another catheter was inserted into a dorsal hand vein of the contralateral arm for blood sampling; this hand was kept warm in a heated box to achieve arterialization of the venous blood (9). After drawing a blood sample, the catheter was flushed with heparinized saline $(2.5 \mathrm{U} / \mathrm{mL})$. Subjects were

Table 1. Physical characteristics of the study population

\begin{tabular}{|c|c|c|c|c|c|c|c|}
\hline & \multirow[b]{2}{*}{ Sex } & \multirow[b]{2}{*}{ Age (y) } & \multirow{2}{*}{$\begin{array}{l}\text { BW } \\
\text { (kg) }\end{array}$} & \multirow{2}{*}{$\begin{array}{c}\text { FFM } \\
(\mathrm{kg})\end{array}$} & \multicolumn{2}{|c|}{$\mathrm{W} \max$} & \multirow{2}{*}{$\frac{\mathrm{VO}_{2} \max }{(\mathrm{ml} / \mathrm{min} / \mathrm{kg})^{*}}$} \\
\hline & & & & & $(W)$ & $(\mathrm{W} / \mathrm{kg})^{*}$ & \\
\hline \multicolumn{8}{|c|}{ CID patients } \\
\hline 1 & $\mathrm{~F}$ & 29 & 55.0 & 43.4 & 60 & 1.09 & 13.1 \\
\hline 2 & $\mathrm{~F}$ & 23 & 61.0 & 45.0 & 60 & 0.98 & 12.3 \\
\hline 3 & $\mathrm{~F}$ & 16 & 47.0 & 36.2 & 55 & 1.17 & 17.7 \\
\hline Mean & & 23 & 54.3 & 41.5 & 58 & 1.08 & 14.4 \\
\hline $\mathrm{SD}$ & & 6 & 7.0 & 4.7 & 3 & 0.10 & 2.9 \\
\hline \multicolumn{8}{|c|}{ Controls } \\
\hline 1 & $\mathrm{~F}$ & 24 & 59.0 & 46.3 & 210 & 3.56 & 41.9 \\
\hline 2 & $\mathrm{~F}$ & 18 & 54.0 & 41.6 & 260 & 4.81 & 54.3 \\
\hline 3 & $\mathrm{~F}$ & 24 & 55.0 & 44.0 & 240 & 4.36 & 46.1 \\
\hline 4 & $\mathrm{~F}$ & 27 & 65.1 & 50.1 & 200 & 3.07 & 33.9 \\
\hline 5 & M & 22 & 70.3 & 66.3 & 340 & 4.84 & 65.7 \\
\hline 6 & $\mathrm{M}$ & 32 & 83.0 & 73.0 & 300 & 3.61 & 42.0 \\
\hline Mean & & 25 & 64.4 & 53.6 & 258 & 4.04 & 47.3 \\
\hline SD & & 5 & 11.0 & 13.0 & 54 & 0.73 & 11.2 \\
\hline
\end{tabular}

* Maximal workload (Wmax) and maximal oxygen uptake $\left(\mathrm{VO}_{2} \mathrm{max}\right)$ are expressed per kilogram body weight (BW) FFM, fat-free mass. 
acclimatized to room conditions (temperature $21-25^{\circ} \mathrm{C}$ ) on a bed in the supine position for $30 \mathrm{~min}$. After a basal blood and urine sample was obtained at $0830 \mathrm{~h}$ (time $0 \mathrm{~min}$ ), a primed constant-rate infusion of $\left[6,6-{ }^{2} \mathrm{H}_{2}\right]$ glucose $(98 \%$ enriched, Mass Trace, Woburn, MA, U.S.A.) was started and continued for $4.5 \mathrm{~h}$ (prime: $15 \mu \mathrm{mol} / \mathrm{kg}$, continuous infusion rate 0.15 $\mu \mathrm{mol} / \mathrm{kg} / \mathrm{min})$. Subjects then rested in the supine position for $3 \mathrm{~h}$ (time 0 to $180 \mathrm{~min}$ ). After this resting period, they stepped from the bed onto the cycle ergometer. Then they performed stationary cycle exercise, at a workload as described above, for $90 \mathrm{~min}$ (time 180 to $270 \mathrm{~min}$ ).

Triacylglycerol infusion. In the triacylglycerol infusion studies, an infusion of Intralipid (Fresenius Kabi, 's Hertogenbosch, The Netherlands) $20 \% \mathrm{wt} / \mathrm{vol}(1.85 \mathrm{mg} / \mathrm{kg} / \mathrm{min}$ of triacylglycerol) plus heparin $(7.5 \mathrm{U} / \mathrm{kg} / \mathrm{h}$, prime $14 \mathrm{U} / \mathrm{kg})$ was initiated at time 0 and maintained throughout the 4.5 -h study (rest and exercise).

Blood sampling and urine collection. Blood samples were drawn at regular intervals at rest and during exercise, placed on ice, and transferred into sodium fluoride tubes for plasma glucose and lactate measurements and lithium-heparinized tubes for FFA determination, and whole blood was deproteinized for measurement of blood pyruvate. Samples for determination of deuterium enrichments were immediately deproteinized with $\mathrm{Ba}(\mathrm{OH})_{2}$ and $\mathrm{ZnSO}_{4}$, centrifuged at $4^{\circ} \mathrm{C}$, and stored at $-70^{\circ} \mathrm{C}$. Subjects voided at time 180 and $270 \mathrm{~min}$ and urine was collected for determination of deuterium enrichment of body water.

\section{Sample Analysis}

Plasma glucose and lactate concentrations were determined enzymatically using autoanalyzers (Dimension AR and ACA SX, Dade Behring, Deerfield, IL, U.S.A.). The concentrations of $\left[6,6-{ }^{2} \mathrm{H}_{2}\right]$ glucose used for the tracer infusions were measured with the autoanalyzer using calibration curves from weighted, water-free glucose (Merck, Darmstadt, Germany). Blood pyruvate and plasma FFA were measured using automated enzymatic colorimetric methods (COBAS FARA II, Hoffmann-La Roche, Montpellier, France). The deuterium enrichment of hydrogen on C-6 of glucose was measured as described previously (10). Briefly, glucose was isolated from deproteinized plasma by successive ion-exchange chromatography and HPLC. C-6 of glucose was converted into formaldehyde and then condensed with ammonium hydroxide to form hexamethylenetetramine, which was analyzed on a gas chromatography mass spectrometry system (HP 5970 equipped with an HP 5890 gas chromatograph, Hewlett Packard, Palo Alto, CA, U.S.A.). Electron impact ionization $(70 \mathrm{eV})$ was used, and ions at mass-to-charge ratio $(\mathrm{m} / \mathrm{z}) 140$ and 141 were monitored using the selected-ion monitoring software. Plasma $\left[6,6-{ }^{2} \mathrm{H}_{2}\right]$ glucose enrichments were measured in the pentaacetate derivative, using electron impact ionization, selected ion monitoring at $\mathrm{m} / \mathrm{z} 200$ and 202. Glucose enrichments were corrected (by subtraction) for increased background enrichment due to the administration of ${ }^{2} \mathrm{H}_{2} \mathrm{O}$. This increase in background enrichment was studied in an additional control subject and was found to be stable over time at rest and during exercise, both when fasting and during triacylglycerol administration (data not shown). Standard solutions of glucose of known enrichment were run along with unknowns to calibrate for instrument variations. Enrichment of deuterium in urine water was determined in acetylene gas by mass spectrometry system, according to Previs et al. (11). Briefly, urine samples were reacted with calcium carbide to form acetylene gas, in which deuterium enrichment was determined by gas chromatography electron impact ionization mass spectrometry. All samples were reacted in triplicate and the measured deuterium enrichments showed a coefficient of variation $<5 \%$.

\section{Calculations}

Rate of appearance of glucose. At rest, steady state wholebody glucose turnover was calculated as follows (12): glucose $\mathrm{Ra}(\mu \mathrm{mol} / \mathrm{kg} / \mathrm{min})=\mathrm{I} / \mathrm{TTR}$, where $\mathrm{I}$ is the infusion rate of the $\left[6,6-{ }^{2} \mathrm{H}_{2}\right]$ glucose tracer in $\mu \mathrm{mol} / \mathrm{kg} / \mathrm{min}$, and TTR is sampled at 15-min intervals during the final hour of rest (120 to 180 min). Isotopic enrichments were considered to be in steady state when TTR of four consecutive samples had a coefficient of variation $<10 \%$, and a slope not significantly different than zero. During exercise, glucose turnover rates were calculated as described for the resting state from isotopic enrichments in plasma, sampled at 15-min intervals during the final hour of exercise (210-270 min). When isotopic enrichments (during exercise) were not in steady state, Ra was calculated with Steele's equations for non-steady state conditions (13), as follows:

glucose $\mathrm{Ra}(\mu \mathrm{mol} / \mathrm{kg} / \mathrm{min})$

$$
=\frac{\mathrm{I}-\mathrm{V}_{\mathrm{d}}\left[\left(\mathrm{G}_{\mathrm{i}}+\mathrm{G}_{\mathrm{j}}\right) / 2\right] *(\Delta \mathrm{TTR} / \Delta \mathrm{T})}{\left(\mathrm{TTR}_{\mathrm{i}}+\mathrm{TTR}_{\mathrm{j}}\right) / 2}
$$

where $V_{d}$ is the volume of distribution of glucose in $\mathrm{mL} / \mathrm{kg}$ [200 $\mathrm{mL} / \mathrm{kg}(14)],\left(\mathrm{G}_{\mathrm{i}}+\mathrm{G}_{\mathrm{j}}\right) / 2$ is the mean plasma glucose concentration (in $\mu \mathrm{mol} / \mathrm{mL}$ ) measured at time points $T_{i}$ and $T_{j}$, $\Delta$ TTR is the change in TTR from $T_{i}$ to $T_{j}, \Delta T$ is the time interval $\left(\mathrm{T}_{\mathrm{j}}-\mathrm{T}_{\mathrm{i}}\right)$ in minutes, and $\left(\mathrm{TTR}_{\mathrm{i}}+\mathrm{TTR}_{\mathrm{j}}\right) / 2$ is the mean TTR measured at time points $T_{i}$ and $T_{j}$.

$\boldsymbol{G N G}$. The contribution of GNG via pyruvate to the production of glucose was estimated by the appearance of ${ }^{2} \mathrm{H}$ on carbon (C)-6 of glucose $(3,5)$. C-6 of glucose is formed from the $\mathrm{C}-3$ (methyl) of pyruvate, thus the deuterium enrichment of hydrogen on glucose C-6 is a measure of $\mathrm{GNG}_{\mathrm{PYR}}$. Because the hydrogen on the methyl carbon of pyruvate equilibrates with body water via exchange, their enrichment would be the same as that of body water (or in this case urine water). Therefore, the deuterium enrichment of the body water can be used as a measure of the deuterium enrichment of hydrogen on C-3 of pyruvate.

fractional contribution of $\mathrm{GNG}_{\mathrm{PYR}}$ to total glucose production (fractional $\left.\mathrm{GNG}_{\mathrm{PYR}}, \%\right)=100 \% \times\left(0.5 \times{ }^{2} \mathrm{H}\right.$ enrichment of glucose $\mathrm{C}-6 /{ }^{2} \mathrm{H}$ enrichment in body water)

The ${ }^{2} \mathrm{H}$ enrichment on C-6 is multiplied by 0.5 because both hydrogen atoms bound to $\mathrm{C}-6$ of glucose are enriched. 
absolute rate of $\mathrm{GNG}_{\mathrm{PYR}}(\mu \mathrm{mol} / \mathrm{kg} / \mathrm{min})=$ glucose $\mathrm{Ra} \times$ fractional $\mathrm{GNG}_{\mathrm{PYR}}$

The lack of complete equilibration of the hydrogen in pyruvate with those of body water may lead to underestimation of $\mathrm{GNG}_{\mathrm{PYR}}$. In normal subjects after prolonged fast, the equilibrium between the hydrogen in pyruvate and body water has been estimated to be $80 \%$ complete (3). We have no reason to believe that this would be different between overnight fasted control or CID subjects. Inasmuch as the equilibrium is $80 \%$ after a prolonged fast, the $\mathrm{GNG}_{\mathrm{PYR}}$ reported here will be underestimated by $20 \%$. It would be of the same magnitude in all the study situations presented.

Statistical analysis. The results are presented as means \pm SD. Because control data were normally distributed whereas patient data were not, parametric and nonparametric statistical methods were used for comparison within both groups: $t$ tests and Wilcoxon rank sum tests for paired data in controls and patients, respectively. Between-group comparisons were made using nonparametric Mann-Whitney tests. Statistical significance was set at $p<0.05$.

\section{RESULTS}

\section{Plasma Concentrations}

Fasting studies. There were no significant differences in plasma glucose concentrations between patients and controls at all times (Table 2). Plasma lactate and blood pyruvate levels as well as lactate-to-pyruvate molar ratios decreased slightly from rest to exercise in controls, whereas concentrations of lactate and pyruvate and their molar ratios increased 2- to 3-fold during exercise in CID patients to values significantly different from those in controls (all $p<0.001$ ). Plasma FFA concentrations in controls increased nearly 3 -fold during exercise, when compared with rest. The increase in FFA levels during exercise was much less marked in patients than in controls, with significantly lower levels during exercise in patients as a consequence $(p<0.05)$.

Triacylglycerol infusion studies. There were no significant differences in plasma glucose concentrations between patients and controls at all times. Plasma lactate and blood pyruvate levels as well as lactate-to-pyruvate ratios remained unchanged from rest to exercise in controls. In patients, exercise elicited similar increases in lactate and pyruvate concentrations and their molar ratios when compared with the fasting studies. Lactate and pyruvate levels and their molar ratios during exercise were significantly higher in patients than in controls (all $p<0.01$ ). Plasma FFA concentrations did not increase from rest to exercise in patients, whereas there was a small increase in controls. There were no differences in FFA concentrations between patients and controls, neither at rest nor during exercise. Plasma FFA concentrations at rest were significantly higher during the triacylglycerol infusion studies in both patients and controls when compared with the fasting studies $(p<0.05$ and $p<0.01$, in patients and controls, respectively). In CID patients, plasma FFA levels during exercise were significantly higher during the triacylglycerol infusion studies, when compared with the fasting studies $(p<$ 0.05). In contrast, there was no significant change in FFA levels during exercise in the control subjects.

\section{Fractional GNG $_{P Y R}$}

Fasting studies. Fractional contribution of $\mathrm{GNG}_{\mathrm{PYR}}$ to glucose Ra increased only slightly during the final hour of the resting period (from 120 to $180 \mathrm{~min}$ ) in both patients and controls (Table 3). Fractional $\mathrm{GNG}_{\mathrm{PYR}}$ remained unchanged in response to exercise in control subjects, whereas it increased on average $17 \%$ in response to exercise in the three patients. It reached maximum values after $30 \mathrm{~min}$ of exercise in CID patient 2 , and after $60 \mathrm{~min}$ of exercise in the other two patients. Fractional $\mathrm{GNG}_{\mathrm{PYR}}$ was significantly increased in patients when compared with controls, both at rest and during exercise (both $p<0.05$, Table 4).

Triacylglycerol infusion studies. Triacylglycerol infusion caused an increase in fractional $\mathrm{GNG}_{\text {PYR }}$ by $\sim 21 \%$ in control subjects during rest $(p<0.05)$, whereas there was no change in the CID patients (Tables 3 and 4). During exercise, fractional contribution of $\mathrm{GNG}_{\mathrm{PYR}}$ to glucose Ra remained unchanged in the controls. In CID patients, fractional $\mathrm{GNG}_{\mathrm{PYR}}$

Table 2. Plasma metabolite concentrations in fasting and triacylglycerol infusion studies

\begin{tabular}{|c|c|c|c|c|}
\hline & \multicolumn{2}{|c|}{ Rest } & \multicolumn{2}{|c|}{ Exercise } \\
\hline & CID patients & Controls & CID patients & Controls \\
\hline \multicolumn{5}{|l|}{ Fasting studies } \\
\hline Plasma lactate $(\mathrm{mmol} / \mathrm{L})$ & $1.2 \pm 0.2 \S$ & $0.8 \pm 0.1$ & $4.1 \pm 0.8^{*}$ & $0.6 \pm 0.1$ \\
\hline Blood pyruvate $(\mu \mathrm{mol} / \mathrm{L})$ & $93 \pm 21$ & $74 \pm 7$ & $176 \pm 17^{*}$ & $64 \pm 5$ \\
\hline Lactate/pyruvate ratio & $13.5 \pm 1.0 \S$ & $10.7 \pm 0.6$ & $22.5 \pm 2.2^{*}$ & $9.4 \pm 1.0$ \\
\hline Plasma glucose $(\mathrm{mmol} / \mathrm{L})$ & $4.9 \pm 0.3$ & $4.7 \pm 0.1$ & $5.1 \pm 0.2$ & $4.5 \pm 0.1$ \\
\hline Plasma lactate $(\mathrm{mmol} / \mathrm{L})$ & $1.1 \pm 0.1 \ddagger$ & $0.6 \pm 0.1$ & $4.0 \pm 1.0 \%$ & $0.7 \pm 0.1$ \\
\hline Blood pyruvate $(\mu \mathrm{mol} / \mathrm{L})$ & $78 \pm 10$ & $58 \pm 8$ & $161 \pm 20 t$ & $69 \pm 20$ \\
\hline Lactate/pyruvate ratio & $14.0 \pm 1.2$ & $11.3 \pm 1.6$ & $24.3 \pm 4.3 \$$ & $11.5 \pm 1.6$ \\
\hline Plasma FFA $(\mu \mathrm{mol} / \mathrm{L})$ & $1258 \pm 272 \S$ & $1236 \pm 88 t$ & $1370 \pm 243 \S$ & $1510 \pm 74$ \\
\hline
\end{tabular}

Values are means $\pm \mathrm{SD}$ in three patients and six controls. ${ }^{*} p<0.001, \ddagger p<0.01, \S p<0.05$ patients $v s$ controls (Mann-Whitney test). $\ddagger p<0.01, \S p<$ 0.05 triacylglycerol infusion $v s$ fasting state (Wilcoxon rank sum test and $t$ test in patients and controls, respectively). Rest, mean value from final hour of rest (120-180 $\mathrm{min})$; exercise, mean value from final hour of exercise (210-270 $\mathrm{min})$. 
Table 3. Contribution of $G N G_{P Y R}$ to total glucose production (as percentage of glucose Ra) in fasting and triacylglycerol infusion studies in individual CID patients and controls

\begin{tabular}{|c|c|c|c|c|c|c|c|c|c|c|c|}
\hline & \multicolumn{5}{|c|}{ Fasting } & \multicolumn{6}{|c|}{ Triacylglycerol infusion } \\
\hline & \multicolumn{2}{|c|}{ Rest (min) } & \multicolumn{3}{|c|}{ Exercise (min) } & \multicolumn{3}{|c|}{ Rest (min) } & \multicolumn{3}{|c|}{ Exercise (min) } \\
\hline & 120 & 180 & 210 & 240 & 270 & 0 & 120 & 180 & 210 & 240 & 270 \\
\hline \multicolumn{12}{|c|}{ CID patient } \\
\hline 1 & 41.3 & 46.2 & 46.8 & 57.4 & 48.9 & 45.9 & 51.4 & 52.7 & 55.4 & 56.8 & 60.8 \\
\hline 2 & 50.0 & 48.8 & 55.6 & 52.8 & & 39.5 & 38.6 & 40.9 & 55.3 & 51.3 & \\
\hline 3 & 49.0 & 53.1 & 63.1 & 69.0 & 60.7 & 52.3 & 52.3 & 56.8 & 61.1 & 58.9 & 58.9 \\
\hline $\mathrm{SD}$ & 4.8 & 3.5 & 8.2 & 8.3 & 5.9 & 6.4 & 7.7 & 8.3 & 3.3 & 3.9 & 1.0 \\
\hline \multicolumn{12}{|c|}{ Controls $(n=6)$} \\
\hline Mean & 38.5 & 38.9 & 40.6 & 41.4 & 38.3 & 36.0 & 49.7 & 44.5 & 48.0 & 46.0 & 41.4 \\
\hline $\mathrm{SD}$ & 5.3 & 5.5 & 6.4 & 5.6 & 9.0 & 0.3 & 3.3 & 1.0 & 5.0 & 4.0 & 4.4 \\
\hline
\end{tabular}

increased significantly during exercise and triacylglycerol infusion. However, the magnitude of increase was similar to that observed in the fasting studies (Table 4).

\section{Rate of Glucose Appearance and Absolute GNG $_{P Y R}$}

Changes in glucose $\mathrm{Ra}$ in response to exercise were generally small and not statistically significant. Glucose $\mathrm{Ra}$ in patients tended to be higher during exercise than at rest. There were no significant differences in glucose Ra between patients and controls at rest and during exercise, both during fasting or triacylglycerol infusion (Table 4).

Absolute rate of $G N G_{P Y R}$ - fasting studies. At rest, absolute $\mathrm{GNG}_{\mathrm{PYR}}$ in patients tended to be increased, but were not significantly different, from those in controls. In response to exercise, $\mathrm{GNG}_{\mathrm{PYR}}$ remained unchanged in controls: $3.8 \pm 0.6$ $\mu \mathrm{mol} / \mathrm{kg} / \mathrm{min}$ at rest versus $4.0 \pm 0.7 \mu \mathrm{mol} / \mathrm{kg} / \mathrm{min}$ during exercise. In patients, however, $\mathrm{GNG}_{\mathrm{PYR}}$ increased from $4.5 \pm$ $1.4 \mu \mathrm{mol} / \mathrm{kg} / \mathrm{min}$ at rest to $7.4 \pm 1.9 \mu \mathrm{mol} / \mathrm{kg} / \mathrm{min}$ during exercise. Absolute $\mathrm{GNG}_{\mathrm{PYR}}$ was $\sim 85 \%$ increased during exercise in patients when compared with controls $(p<0.01)$.

Absolute rate of $G N G_{P Y R}$-triacylglycerol infusion studies. In resting controls, absolute gluconeogenic rates from pyruvate during triacylglycerol infusion were significantly increased when compared with the fasting studies $(p<0.05)$. In response to exercise, absolute $\mathrm{GNG}_{\mathrm{PYR}}$ remained unchanged in controls, whereas in patients it increased from $5.1 \pm 1.8 \mu \mathrm{mol} / \mathrm{kg} / \mathrm{min}$ at rest to $7.9 \pm 1.2 \mu \mathrm{mol} / \mathrm{kg} / \mathrm{min}$. In analogy with the fasting studies, absolute $\mathrm{GNG}_{\mathrm{PYR}}$ was significantly increased ( 72\%) during exercise in CID patients, when compared with controls $(p<0.01)$.

\section{DISCUSSION}

The present study shows that, during low-intensity exercise, the rate of $\mathrm{GNG}_{\mathrm{PYR}}$ is substantially elevated in patients with a respiratory chain disorder due to CID compared with the rates in healthy controls. Pyruvate levels were always higher in patients than in controls, both at rest and during exercise. Compared with fasting, triacylglycerol infusion was neither associated with an increased rate of $\mathrm{GNG}_{\mathrm{PYR}}$ during rest nor during exercise. In controls, triacylglycerol infusion caused a small increase in $\mathrm{GNG}_{\mathrm{PYR}}$ only during rest but not during exercise. We discuss the significance of the findings in the context of lactate pathophysiology and possible dietary treatment in CID.

As far as reflected by circulating levels, pyruvate availability for GNG in our CID patients was 3-fold increased during exercise, when their $\mathrm{GNG}_{\mathrm{PYR}}$ was found to be increased. At rest, when pyruvate levels were also higher in patients than in controls, rates of $\mathrm{GNG}_{\mathrm{PYR}}$ tended to be higher in patients than in controls, accordingly. These findings suggest that differences in substrate (pyruvate) availability may have contributed to the rate of GNG from pyruvate both during fasting and during triacylglycerol infusion. It is of interest that this is observed in CID patients, in whom the cytosolic redox poten-

Table 4. Rate of appearance of glucose and contribution of $G N G_{P Y R}$ in fasting and triacylglycerol studies in CID patients and controls

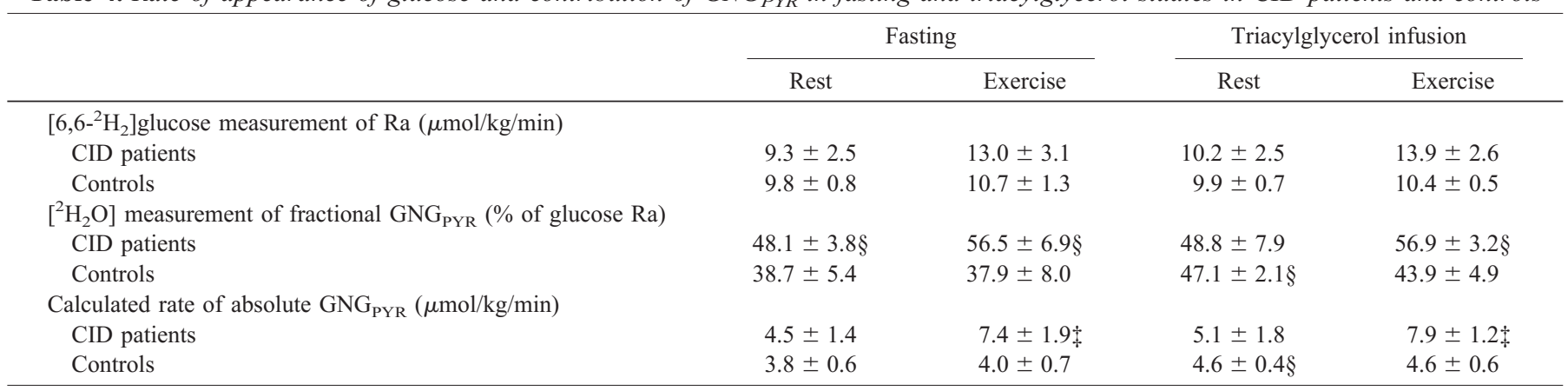

Values are means \pm SD in three CID patients and six controls. $\$ p<0.01, \S p<0.05$ patients $v s$ controls (Mann-Whitney test), or triacylglycerol infusion $v s$ fasting in resting control study (paired $t$ test). Rest, mean value measured/calculated during final hour of rest (120-180 min); exercise, mean value measured/calculated during final hour of exercise (210-270 min). 
tial is reduced as reflected by their higher lactate-to-pyruvate molar ratio in plasma. In healthy human subjects, and in patients with non-insulin-dependent diabetes mellitus, ethanol intake diminishes cellular redox potential and the rate of $\mathrm{GNG}_{\mathrm{PYR}}(15,16)$. As ethanol reduces both the redox potential and the pyruvate level, causal effects between the altered redox state or decreased pyruvate availability cannot be discriminated with respect to the observed lower $\mathrm{GNG}_{\mathrm{PYR}}$ in these studies. Krebs et al. (17) have shown that inhibition of GNG from lactate by ethanol in perfused rodent liver was abolished when the experiments were corrected for the lowering effect of ethanol on the pyruvate concentration. In line with the latter observations, our results in CID patients at rest and during exercise demonstrate that GNG from pyruvate is maintained in the presence of a diminished cellular redox state, and can even be elevated under the condition of a further reduction of the redox potential when pyruvate availability is high.

The increased resting rates of $\mathrm{GNG}_{\mathrm{PYR}}$ during triacylglycerol infusion in the controls, when compared with the fasting state, is in agreement with observations by Chen et al. (18). Whereas these authors suggested a direct relationship between acute changes in GNG and endogenous FFA (by administration of nicotinic acid), our data in control subjects during rest are suggestive of a similar relationship between GNG and FFA of exogenous origin. In fasting control experiments, $\mathrm{GNG}_{\mathrm{PYR}}$ did not change in the transition from rest to exercise, despite a nearly 3-fold increase of FFA levels, making a significant relationship between FFA concentrations and gluconeogenic rates during exercise unlikely. Our finding of a significantly increased rate of $\mathrm{GNG}_{\mathrm{PYR}}$ in CID patients during exercise, despite their lower FFA levels compared with controls, suggests that the effect of substrate (pyruvate) availability is more important than effects of FFA availability on GNG.

A limitation of the present study is the small sample sizes in the patient and control groups, which obscures the possibility to detect small differences in the rates of GNG with sufficient power. $\mathrm{GNG}_{\mathrm{PYR}}$ during triacylglycerol infusion tended to be higher than in the fasting studies in resting CID patients, but the difference was not statistically significant. Similarly, rates of $\mathrm{GNG}_{\mathrm{PYR}}$ were nonsignificantly increased in patients at rest compared with controls both during fasting and during triacylglycerol infusion.

The higher $\mathrm{GNG}_{\mathrm{PYR}}$ during exercise in CID patients receiving the triacylglycerol infusions would provide an argument in support of prescription of high-fat diets to the patients. However, in the absence of data on the effectiveness of such a diet in terms of clinical symptoms or lactate disposal, this inference cannot be made. The effects of carbohydrates, which form part of high-fat diets to increase their palatability, were not studied. We thus cannot speculate further on the usefulness of high-fat diets for CID patients on the basis of our study results.

In summary, results of this study suggest the following: 1) $\mathrm{GNG}_{\mathrm{PYR}}$ is increased during exercise in CID patients, despite reduced cellular redox state. 2) Increased pyruvate availability likely contributes to the stimulated gluconeogenic rates in the CID patients. 3) Increased availability of fatty acids is not associated with increased $\mathrm{GNG}_{\mathrm{PYR}}$ in CID patients, neither at rest nor during exercise.

Acknowledgments. The authors thank Helma Straver and Martina de Barse for technical assistance.

\section{REFERENCES}

1. Roef MJ, de Meer K, Reijngoud D-J, Straver WHC, de Barse M, Kalhan SC, Berger R 2002 Triacylglycerol infusion improves exercise endurance in patients with mitochondrial myopathy due to complex I deficiency. Am J Clin Nutr 75:228-236

2. Roef MJ, de Meer K, Reijngoud D-J, Straver WHC, de Barse M, Kalhan SC, Berger R 2002 Triacylglycerol infusion does not improve hyperlactemia in resting patients with mitochondrial myopathy due to complex I deficiency. Am J Clin Nutr 75:237244

3. Landau BR, Wahren J, Chandramouli V, Schumann WC, Ekberg K, Kalhan SC 1995 Use of ${ }^{2} \mathrm{H}_{2} \mathrm{O}$ for estimating rates of gluconeogenesis: application to the fasted state. $\mathrm{J}$ Clin Invest 95:172-178

4. Landau BR, Wahren J, Chandramouli V, Schumann WC, Ekberg K, Kalhan SC 1996 Contributions of gluconeogenesis to glucose production in the fasted state. J Clin Invest 98:378-385

5. Kalhan S, Rossi K, Gruca L, Burkett E, O’Brien A 1997 Glucose turnover and gluconeogenesis in human pregnancy. J Clin Invest 100:1775-1781

6. Williamson JR, Browning ET, Scholz R 1969 Control mechanisms of gluconeogenesis and ketogenesis. I. Effects of oleate on gluconeogenesis in perfused rate liver. J Biol Chem 244:4607-4616

7. Morand C, Remesy C, Demigne C 1993 Fatty acids are potent modulators of lactate utilization in isolated hepatocytes from fed rats. Am J Physiol 264:E816-E823

8. Gulmans VAM, de Meer K, Brackel HJL, Helders PJM 1997 Maximal work capacity in relation to nutritional status in children with cystic fibrosis. Eur Respir J 10:20142017

9. McGuire EAM, Helderman JH, Tobin JD, Andres R, Berman M 1976 Effects of arterial versus venous sampling on analysis of glucose kinetics in man. J Appl Physiol 41:565-573

10. Kalhan SC, Trivedi R, Singh S, Chandramouli V, Schumann WC, Landau BR 1995 A micromethod for the measurement of deuterium bound to carbon- 6 of glucose to quantify gluconeogenesis in vivo. J Mass Spectrom 30:1588-1592

11. Previs SF, Hazey JW, Diraison F, Beylot M, David F, Brunengraber H 1996 Assay of the deuterium enrichment of water via acetylene. J Mass Spectrom 31:639-642

12. Tserng K, Kalhan SC 1983 Calculation of substrate turnover rate in stable isotope tracer studies. Am J Physiol 245:E308-E311

13. Steele R 1959 Influence of glucose loading and of injected insulin on hepatic glucose output. N Y Acad Med Sci 82:420-430

14. Ann Knapik JJ, Meredith CN, Jones BH, Suek L, Young VR, Evans WJ 1988 Influence of fasting on carbohydrate and fat metabolism during rest and exercise in men. J Appl Physiol 64:1923-1929

15. Yki-Järvinen H, Nikkilä EA 1985 Ethanol decreases glucose utilization in healthy man. J Clin Endocrinol Metab 61:941-945

16. Puhakainen I, Koivisto VA, Yki-järvinen H 1991 No reduction in total hepatic glucose output by inhibition of gluconeogenesis with ethanol in NIDDM patients. Diabetes 40:1319-1327

17. Krebs HA, Freedland RA, Hems R, Stubbs M 1969 Inhibition of hepatic gluconeogenesis by ethanol. Biochem J 112:117-124

18. Chen X, Iqbal N, Boden G 1999 The effects of free fatty acids on gluconeogenesis and glycogenolysis in normal subjects. J Clin Invest 103:365-372 